University of Wollongong

Research Online

Faculty of Engineering and Information

Faculty of Engineering and Information

Sciences - Papers: Part A

Sciences

$1-1-2015$

Real-time eye lens dose monitoring during cerebral angiography procedures

M J. Safari

University of Malaya

J H.D. Wong

University of Malaya

K A.A. Kadir

University of Malaya

N K. Thorpe

University of Wollongong, nkt305@uowmail.edu.au

D L. Cutajar

University of Wollongong, deanc@uow.edu.au

See next page for additional authors

Follow this and additional works at: https://ro.uow.edu.au/eispapers

Part of the Engineering Commons, and the Science and Technology Studies Commons

Research Online is the open access institutional repository for the University of Wollongong. For further information contact the UOW Library: research-pubs@uow.edu.au 


\title{
Real-time eye lens dose monitoring during cerebral angiography procedures
}

\author{
Abstract \\ Objectives: To develop a real-time dose-monitoring system to measure the patient's eye lens dose during \\ neuro-interventional procedures. Methods: Radiation dose received at left outer canthus (LOC) and left \\ eyelid (LE) were measured using Metal-Oxide-Semiconductor Field-Effect Transistor dosimeters on 35 pa- \\ tients who underwent diagnostic or cerebral embolization procedures. Results: The radiation dose \\ received at the LOC region was significantly higher than the dose received by the $L E$. The maximum eye \\ lens dose of $1492 \mathrm{mGy}$ was measured at LOC region for an AVM case, followed by $907 \mathrm{mGy}$ for an \\ aneurysm case and $665 \mathrm{mGy}$ for a diagnostic angiography procedure. Strong correlations (shown as R2) \\ were observed between kerma-area-product and measured eye doses (LOC:0.78, LE: 0.68). Lateral and \\ frontal air-kerma showed strong correlations with measured dose at LOC (AKL:0.93, AKF:0.78) and a \\ weak correlation with measured dose at LE. A moderate correlation was observed between fluoroscopic \\ time and dose measured at LE and LOC regions. Conclusions: The MO Skin dose-monitoring system \\ represents a new tool enabling real-time monitoring of eye lens dose during neuro-interventional \\ procedures. This system can provide interventionalists with information needed to adjust the clinical \\ procedure to control the patient's dose. Key Points • Real-time patient dose monitoring helps \\ interventionalists to monitor doses. - Strong correlation was observed between kerma-area-product and \\ measured eye doses. • Radiation dose at left outer canthus was higher than at left eyelid \\ Disciplines \\ Engineering | Science and Technology Studies

\section{Publication Details} \\ Safari, M. J., Wong, J. H.D.., Kadir, K. A.A.., Thorpe, N. K., Cutajar, D. L., Petasecca, M., Lerch, M. L. F., \\ Rosenfeld, A. B. \& Ng, K. H. (2016). Real-time eye lens dose monitoring during cerebral angiography \\ procedures. European Journal of Radiology, 26 (1), 79-86.

\section{Authors} \\ M J. Safari, J H.D. Wong, K A.A. Kadir, N K. Thorpe, D L. Cutajar, M Petasecca, M L. F Lerch, A B. Rosenfeld, \\ and K. H. Ng
}




\section{Real-time eye lens dose monitoring during cerebral}

\section{angiography procedures}

M.J. Safari ${ }^{1,2}$, J.H.D. Wong ${ }^{1,2}$, K.A. Abd Kadir ${ }^{1,2}$, N. Thorpe ${ }^{3}$, D.L.

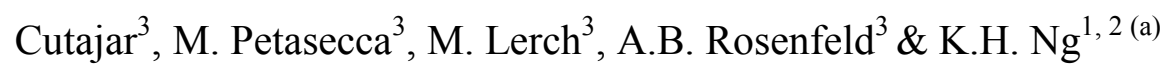

1) Department of Biomedical Imaging, Faculty of Medicine, University of Malaya, Kuala Lumpur, Malaysia

2) University of Malaya Research Imaging Centre (UMRIC), Faculty of Medicine, University of Malaya, Kuala Lumpur, Malaysia

3) Centre for Medical Radiation Physics (CMRP), University of Wollongong, Wollongong, Australia

(a) Corresponding author: Prof. Dr. Ng Kwan Hoong Mailing address: Department of Biomedical Imaging, Faculty of Medicine, University of Malaya, 50603 Kuala Lumpur, Malaysia

Tel. No. (Office): 03-7949 2038

Fax No.: 03- 79581973

E-mail Address:ngkh@um.edu.my 
Abstract Objectives: The purpose of this study was to develop a real-time dose monitoring system to measure the patient's eye lens dose during neurointerventional procedures. Methods: Radiation dose received at left outer canthus (LOC) and left eyelid (LE) were measured using Metal-OxideSemiconductor Field-Effect Transistor dosimeters on 35 patients who underwent diagnostic or cerebral embolization procedures. Results: The radiation dose received at the $\mathrm{LOC}$ region was significantly higher than the dose received by the LE. The maximum eye lens dose of 1492 mGy was measured at LOC region for an AVM case, followed by 907 mGy for an aneurysm case and $665 \mathrm{mGy}$ for a diagnostic angiography procedure. Strong correlations were observed between kerma-area-product and measured eye doses (LOC: 0.78, LE: 0.68). Lateral and frontal air-kerma showed strong correlations with measured dose at $\mathrm{LOC}\left(\mathrm{AK}_{\mathrm{L}}: 0.93, \mathrm{AK}_{\mathrm{F}}: 0.78\right)$ and weak correlation with measured dose at LE. A moderate correlation was observed between fluoroscopic time and dose measured at LE and LOC regions. Conclusions: The MOSkin dose monitoring system represents a new tool enabling real-time monitoring of patient's eye lens dose during neurointerventional procedures. This system can provide interventionalists with information needed to adjust the clinical procedure to control the patient's dose. 


\section{Keywords:}

Interventional radiology, Cerebral angiography, Eye lens, Patient dose, Realtime dose monitoring

\section{Key point:}

1. Real-time patient dose monitoring helps interventionalists to monitor patient's dose.

2. Strong correlation was observed between kerma-area-product and measured patients' eye doses

3. Radiation dose at patients' left outer canthus was higher than left eyelid

\section{Abbreviation list:}

1. $\mathrm{FT}=$ Fluoroscopic time

2. $\mathrm{KAP}=$ Kerma-area-product

3. $\mathrm{AK}=$ Air kerma

4. $I R P=$ Interventional reference point

5. LE $=$ Left eyelid

6. $\mathrm{LOC}=$ Left outer canthus

7. MOSFET=Metal-Oxide-Semiconductor Field-Effect Transistor 


\section{Introduction}

Fluoroscopy-guided interventional radiological procedures provide enormous advantages over invasive surgical procedures. However, long radiation exposure during complicated interventional radiology (IR) procedures remains a concern. Skin injuries are the most frequently encountered tissue reaction effects from IR procedures [1-4]. Different indirect dose evaluation techniques, such as fluoroscopic time (FT), kerma-area-product (KAP), dose level at the interventional reference point (IRP), and peak skin dose, have been established as skin dose indicators for IR procedures $[5,6]$. Other than skin dose, the radiation dose to patient's eye lens is also a concern, particularly for patients undergoing long neuro-interventional procedures. Cataract formations are late effects of radiation exposure. Unlike skin reactions, which are visible after about 2 weeks, they usually appear after 10-20 years. To date, different threshold doses have been proposed for cataract formation during acute radiation exposure. The International Commission on Radiological Protection (ICRP) [7], following recent epidemiology studies [8-11], issued a new statement in 2011 on the threshold of 0.5 Gy in absorbed dose to eye lens. Currently, different direct dosimeters have been used as post-processing dose evaluation methods to evaluate the patient's skin dose and eye lens dose during IR procedures [12-17]. To the best of the authors' knowledge, there is no real- 
time in vivo dosimetry system that has been used for patient dose monitoring during IR procedures.

The purpose of the present study was to: first, demonstrate a new real-time dose monitoring system for determining patient eye lens dose during neurointerventional procedures; and second, to evaluate correlations of the patient eye lens dose with dose metric parameters, like KAP, FT, and AK of the frontal $\left(\mathrm{AK}_{\mathrm{F}}\right)$ and lateral tube $\left(\mathrm{AK}_{\mathrm{L}}\right)$. In this study, our hypothesis was that not all existing dose metric parameters are suitable to indicate patient's eye lens dose.

\section{Materials and Methods}

\section{A. Patients}

The real-time monitoring of eye lens dose was carried out on 35 patients, 24 female patients ( $45 \pm 16.9$ years) and 11 male patients (age $46 \pm 16.8$ years), comprising 19 diagnostic angiographies, 8 treatments of cerebral aneurysms, and 8 embolizations of AVMs. The same interventionalist and radiography team performed the neuro-interventional procedures from March 2013 to March 2014.

\section{B. X-ray equipment}

The neuro-interventional procedures were performed using an Allura Xper 
FD20/20 ${ }^{\circledR}$ biplane system (Philips Healthcare, Best, The Netherlands) at the University of Malaya Medical Centre (UMMC). This suite consists of one ceiling-mounted x-ray tube and one floor-mounted x-ray tube (C-arm) equipped with a $30 \mathrm{~cm} \times 38 \mathrm{~cm}$ dynamic flat detector. This machine is equipped with different electronic rectangular field-of-views (FOVs), which change the sensitive image detector area from $15 \mathrm{~cm}$ to $48 \mathrm{~cm}$ while the exposure tube potential varies between 40 and $125 \mathrm{kVp}$. This machine can generate five frame rate ranges for vascular procedures $(0.5 \mathrm{fps}, 2 \mathrm{fps}, 3 \mathrm{fps}$, $4 \mathrm{fps}$, and 6fps) and two frame rate ranges for cardiac procedures (15fps and 30fps). The tube voltage is controlled by an automatic brightness control system (ABC). The Allura Xper FD20/20 machine can apply different filtrations, $0.2 \mathrm{~mm}, 0.5$, and $1.0 \mathrm{~mm}$ copper equivalent, which are specified to different types of exposures.

\section{C. MOSkin Dosimetry system and measurement setup}

MOSkin detector is a new type of Metal Oxide Semiconductor Field Effect Transistor (MOSFET) detector designed by the Centre for Medical Radiation Physics (CMRP), University of Wollongong, Australia. This detector was specially designed for skin dose measurement and has previously been used for patient skin dose measurement during radiotherapy procedures [18-22]. 
This detector is composed of a hermitically sealed MOSFET detector in a kapton strip using "drop-in" packaging technology [18]. A layer of polyamide film protects and encapsulates the radiosensitive MOSFET sensor, as well as provides a reproducible build-up layer with water equivalent depth of $0.07 \mathrm{~mm}$ [Figure 1]. The principle of operation of the MOSkin detector is based on the change of the threshold voltage $\left(\Delta V_{t h}\right)$, which is proportional to the irradiation dose [19, ("Characterization of MOSkin detector for in vivo skin dose measurement during interventional radiology procedures" by Safari MJ, Wong JHD, Ng KH et al, submitted in September 2014, Medical Physics Journal)]. The MOSkin detector was characterized under Radiation Qualities in Radiation beams emerging from the $\mathrm{x}$-ray tube assembly (RQR) standard beam. This detector proved to be reliable when exposed to different dose rates $( \pm 3 \%)$, frame rates $( \pm 3 \%)$, radiation incident angles $( \pm 5 \%)$, and exposure energies ( $\pm 5 \%$ ) ("Characterization of MOSkin detector for in vivo skin dose measurement during interventional radiology procedures" by Safari MJ, Wong JHD, Ng KH et al, submitted in September 2014, Medical Physics Journal). The MOSkin detector response $\left(\Delta V_{t h}\right)$ can be recorded either manually from the reader or automatically via computer software. In this study, a graphic user interface, FETch, was designed to present the dose values in a more visual form. This interface displays the accumulated dose in column bar charts and 
numeric form [Figure 2 (b)]. Dose measurements can be performed at userdefined readout frequencies (maximum temporal frequency is $1 \mathrm{~Hz}$ ). With this interface, the operators are able to monitor the radiation dose received by the patient in a more intuitive and direct manner, providing valuable information with minimal or no distraction to the interventionalist during a clinical procedure.

\section{B. Data acquisition}

For all the neuro-interventional procedures, the lateral $\mathrm{x}$-ray tube was positioned on the left side of the patients' heads throughout the treatments. A study of the exposure parameters during 53 neuro-interventional procedures showed that, in $73.7 \%$ of the projection times, the frontal tube projections were acquired in the posterior-anterior direction $\left(10^{\circ} \mathrm{RAO}-10^{\circ} \mathrm{LAO}\right)$ and in $93 \%$ of the time the lateral tube direction was changed from $70^{\circ}$ RAO to $90^{\circ} \mathrm{RAO}$. ("An investigation of the contribution of routine radiological exposure parameters to patient's dose during neuro-interventional radiology procedures: A phantom study" by Safari MJ, Wong JHD, Jong WL et al, submitted in March 2015, European Radiology). Therefore, the lenses of the left eyes were constantly exposed to the primary x-ray beam from the lateral x-ray tube. The difference between the radiation doses received in the left and right eyes during 
cerebral angiography procedures were studied in a pilot study on two patients, which revealed that the radiation dose delivered to the left eye region is significantly higher ( $\sim 5$ times) than the dose delivered to the right eye. For this reason, in this study we focused on the measurement of the dose delivered to patients' left eye. The study of the patients' eye lens dose was implemented using MOSkin detectors. The patients were asked to keep their eyes closed during the treatment procedure. Two MOSkin detectors were positioned on the patient's left outer canthus (LOC) and left eyelid (LE) [Figure 3(a)]. This detector is not visible on the displayed image and does not interfere with the treatment procedure [Figure 3(b)]. The MOSkin detectors were placed on the patient's body for at least 5 minutes to allow the detectors to equilibrate with the patient's body temperature before commencing the measurement. The MOSkin dosimetry system equipped with acquisition laptop using FETch software was placed in front of the interventionalist and the radiographer during the treatment procedures [Figure 2(a)]. Exposure parameters were recorded from the console. Measured doses were compared with exposure parameters such as $\mathrm{FT}, \mathrm{KAP}, \mathrm{AK}_{\mathrm{F}}$ and $\mathrm{AK}_{\mathrm{L}}$.

\section{C. Statistical analysis}

Regression correlation tests were carried out to determine the relationships 
between the MOSkin response and total fluoroscopic time, $\mathrm{KAP}, \mathrm{AK}_{\mathrm{L}}$ as well as $\mathrm{AK}_{\mathrm{F}}$. All analyses were carried out using SPSS (version 16, SPSS, Chicago, IL).

\section{Results}

\section{A. Patient's eye lens dose}

The average dose received at the outer canthus and eyelid regions showed that the radiation dose received at the outer canthus region was significantly higher than the dose received at the eyelid region [Table 1]. The range of the AK for each tube and, consequently, KAP for AVM procedures, was higher than for other procedures. Due to higher dose delivery in AVM procedures, patients received higher dose at the outer canthus and eyelid locations [Table 1 and Figure 4].

Figure 5 shows the correlation between the exposure parameters and received dose at LE and LOC. There is a strong correlation between accumulative KAP and dose values at $L E$ and $L O C$ regions $\left(L O C: R^{2}=0.78\right.$ and $L E: R^{2}=0.68$ ) [Figure 5 (a)]. Moderate correlations were observed between total fluoroscopic time and dose at LE and LOC (LOC: $\mathrm{R}^{2}=0.52$ and LE: $\left.\mathrm{R}^{2}=0.40\right)$ [Figure 5 (b)]. The accumulative AK for lateral and frontal tubes shows a strong correlation with measured dose at $\mathrm{LOC}\left(\mathrm{AK}_{\mathrm{L}}: 0.93\right.$ and $\left.\mathrm{AK}_{\mathrm{F}}: 0.78\right)$ [Figure $\left.5(\mathrm{c}, \mathrm{d})\right]$ but a 
weak correlation with measured dose at $\mathrm{LE}\left(\mathrm{AK}_{\mathrm{L}}: 0.28\right.$ and $\left.\mathrm{AK}_{\mathrm{F}}: 0.10\right)$ [Figure $5(\mathrm{c}, \mathrm{d})]$.

\section{B. Study of exposure parameters}

Figure 6 shows the accumulated dose trend at LOC for a particular AVM case, highlighting the unique capability of the MOSkin dosimetry system. Using the MOSkin detector, we can study the trend of the patient's accumulated dose during an interventional procedure. By matching the MOSkin detector response and exposure time from the console, we can correlate the dose measured by the MOSkin detectors with the machine exposure parameters, thereby understanding their contribution to the patient's received dose. The system not only enables us to record real-time patient dose, but also enables us to investigate the contribution of each exposure to patient's dose in terms of exposure parameters $(\mathrm{kV}, \mathrm{mAs}$, exposure angulation and rotation and number of frames) [Figure 6] or exposure types (Fluoroscopy, DSA, cine and road mapping) [Figure 7]. From Figure 6, it was found that the sharp increments in the detector threshold voltage were due to high dose rate DSA acquisition technique. For this particular AVM procedure, the DSA contributed $94 \%$ of the total dose to eye lens followed by road mapping $(4.7 \%)$, cine trace $(0.5 \%)$ and fluoroscopy $(0.8 \%)$. This information [Figure $6 \&$ Figure 7 ] is important in 
post-procedure analysis for future dose minimization strategies and can be utilized for the interventionalists' training.

\section{Discussion}

Different techniques have been recommended to reduce radiation dose during IR procedures, such as using pulsed mode fluoroscopy exposure, shortening the exposure time, increasing distance between $\mathrm{x}$-ray source and patient, reducing distance between image receptor and patient, minimizing the magnification, maximizing collimation, using last image hold technique, changing C-arm angles and using low frame rate exposure[23, 24].

Applying these strategies and using a direct dosimetry system can significantly improve patient radiation safety during IR procedures. Direct dose measurement is not feasible for all IR procedures; for this reason, the dose metric parameters (FT, KAP, $\left.\mathrm{AK}_{\mathrm{IRP}}\right)$ are regularly monitored and recorded. To prevent skin injuries, a certain threshold level has been suggested for each parameter, for instance FT 40-60 min, KAP 500 Gy. $\mathrm{cm}^{2}$, IRP 5 Gy and peak skin dose 3 Gy [25]. While these parameters are mostly recorded after each IR procedure as a rough estimate of the radiation dose received by patients, some studies have shown that they do not provide sufficient information during a procedure to control local skin dose to a given patient $[5,6,26,27]$. The actual 
patient's entrance skin dose can be calculated from exposure air kerma at reference point by incorporating table attenuation, backscatter factor, correction of actual source skin distance (Inverse square law) of reference point to actual skin point and correction of mass energy absorption coefficients of skin to air [28]. Recently, automatic skin dose simulation tools were used to estimate the entrance skin dose from the geometrical and exposure information extracted from DICOM tags and system parameters. These software are able to map the estimated skin dose distribution on standard and anatomical patient model phantoms $[28,29]$.

In this study, KAP values showed strong correlation with doses received at LE and LOC regions. For the cerebral angiography procedure, the patient's eyes are frequently exposed to primary radiation beams. This may be the main reason that this strong correlation was observed between KAP and measured dose at LE and LOC regions. In our center, the lateral tube was always placed at the left side of the patient's head, therefore $\mathrm{AK}_{\mathrm{L}}$ and measured doses at $\mathrm{LE}$ and LOC showed strong correlation, unlike the frontal tube, which showed a weak correlation with the measured doses.

For all cases measured dose at LOC was higher than LE. This difference can be explained by two reasons: first, the closer proximity of the LOC detector to the lateral X-ray tube compared to the LE detector; and second, collimation of 
the radiation field. The radiography team was well trained to minimize the irradiation dose to the left eye lens by collimating the radiation field of the lateral tube. With proper collimation of the radiation field, the detector on the eyelid would be out of direct radiation from the lateral tube, while the detector on the outer canthus would still be within the direct beam. The collimation effect would be significant for embolization procedures at the posterior region of the skull, which can completely place the patient's eyes outside of the primary beam. This finding clearly shows the importance of choosing the right location for the point dose measurement during a non-homogenous dose distribution procedure. The maximum eye lens dose of 1492 mGy was measured at LOC region for an AVM case, followed by $907 \mathrm{mGy}$ for an aneurysm case and $665 \mathrm{mGy}$ for a diagnostic angiography procedure.

This study showed that among the 35 patients, LOC regions of 8 patients and LE region of 1 patient were found to receive higher doses than the assumed threshold dose for cataract formation (500 mGy). Recent studies have reported the average and maximum patient eye doses for neuro-interventional radiology procedures [Table 2]. Generally, therapeutic procedures are more complicated than diagnostic procedures, which lead to longer exposure time and higher dose delivery to patients' bodies (KAP). The results of our study are in good agreement with previous studies. As shown, the detectors positioned at the 
lateral margin received higher doses in comparison to those placed on the eyelids or inferior and superior margins (I-S margins).

As a high frame rate and high quality imaging technique, DSA plays a major role in contributing to patient's dose. Some studies have tried to evaluate the effect of DSA exposure on patient dose $[30,31]$. The MOSkin detector enables us to study the contribution of various exposure parameters on patient's dose during a clinical procedure. However, the main objective of the patient dosimetry is to monitor the total dose delivered to the patient's body as well as the dose delivered to the sensitive organs. A real-time dose monitoring system can provide real-time information for each particular exposure. This information can be used to study the techniques to optimize patient's radiation safety during IR procedures, such as changing the exposure angulation, adjusting the exposure collimation, and shortening the exposure time when the dose at detector position reaches a critical level.

In summary, indirect dose measurements using machine available dose metrics such as KAP, FT and air kerma are not accurate indicators of the actual dose received by patients undergoing interventional radiological procedures. This information can only be obtained via actual in-vivo dose measurements. In this work, we demonstrated the feasibility of using the MOSkin dose monitoring system as a real time, in-vivo dose measurement system. The system was 
successfully used to measure patient eye lens dose during neuro-interventional procedures. This system enables interventionalists to have better awareness of the patient's eye lens dose during clinical procedures.

\section{Acknowledgement}

The authors acknowledge and thank the personnel at the following institutions for their technical support in this study: C.C. Lee and M. Mozaker, radiographers at the University Malaya Medical Centre (UMMC) and K.H. Lam from Philips Healthcare Malaysia. This study was supported by the High Impact Research (HIR) grant, UM.C/625/1/HIR/MOHE/MED/38, account no: H-20001-00-E000077 and PPP grant, PG035-2013A from the University of Malaya. The current research project was approved by the medical ethics committee of University of Malaya Medical Centre (UMMC), no 1024.22. 
1. Mooney RB, McKinstry CS, and Kamel HA (2000) Absorbed dose and deterministic effects to patients from interventional neuroradiology. $\mathrm{Br} \mathrm{J}$ Radiol 871:745-51

2. Wagner LK, McNeese MD, Marx MV, and Siegel EL (1999) Severe skin reactions from interventional fluoroscopy: case report and review of the literature. Radiology 3:773-776

3. Balter S, Hopewell JW, Miller DL, Wagner LK, and Zelefsky MJ (2010) Fluoroscopically guided interventional procedures: a review of radiation effects on patients' skin and hair. Radiology 2:326-341

4. Spiker A, Zinn Z, Carter WH, Powers R, and Kovach R (2012) Fluoroscopy-induced chronic radiation dermatitis. Am J Cardiol 12:18611863

5. Jaco JW and Miller DL (2010) Measuring and monitoring radiation dose during fluoroscopically guided procedures. Tech Vasc Interv Radiol 3:188193

6. Balter S, Fletcher DW, Kuan HM, et al. (2002) Techniques to estimate radiation dose to skin during fluoroscopically guided procedures $\alpha$. Skin Dose Measurements AAPM 1-10

7. Stewart FA, Akleyev AV, Hauer-Jensen M, et al. (2012) ICRP publication 118: ICRP statement on tissue reactions and early and late effects of radiation in normal tissues and organs--threshold doses for tissue reactions in a radiation protection context. Ann ICRP 1-2:1-322

8. Worgul BV, Kundiyev YI, Sergiyenko NM, et al. (2007) Cataracts among Chernobyl clean-up workers: implications regarding permissible eye exposures. Radiat Res 2:233-243 
9. Chodick G, Bekiroglu N, Hauptmann M, et al. (2008) Risk of cataract after exposure to low doses of ionizing radiation: a 20-year prospective cohort study among US radiologic technologists. Am J Epidemiol 6:620-631

10. Vano E, Kleiman NJ, Duran A, Rehani MM, Echeverri D, and Cabrera M (2010) Radiation cataract risk in interventional cardiology personnel. Radiat Res 4:490-495

11. Mrena S, Kivela T, Kurttio P, and Auvinen A (2011) Lens opacities among physicians occupationally exposed to ionizing radiation--a pilot study in Finland. Scand J Work Environ Health 3:237-243

12. Theodorakou C and Horrocks JA (2003) A study on radiation doses and irradiated areas in cerebral embolisation. Br J Radiol 908:546-552

13. Meriçı N, Bor D, Ilgıt E, Öznur İ, and Büget N (1998) Comparison of eye lens dose measurement techniques in imaging and interventions of the lachrymal drainage system. Phys Med 3:95-100

14. Schueler BA, Kallmes DF, and Cloft HJ (2005) 3D cerebral angiography: radiation dose comparison with digital subtraction angiography. AJNR Am J Neuroradiol 8:1898-901

15. Ilgit ET, Meric N, Bor D, Oznur I, Konus O, and Isik S (2000) Lens of the eye: radiation dose in balloon dacryocystoplasty. Radiology 1:54-57

16. Sandborg M, Rossitti S, and Pettersson H (2010) Local skin and eye lens equivalent doses in interventional neuroradiology. Eur Radiol 3:725-733

17. Moritake T, Matsumaru Y, Takigawa T, Nishizawa K, Matsumura A, and Tsuboi K (2008) Dose measurement on both patients and operators during neurointerventional procedures using photoluminescence glass dosimeters. AJNR Am J Neuroradiol 10:1910-1917 
18. Kwan IS, Wilkinson D, Cutajar D, et al. (2009) The effect of rectal heterogeneity on wall dose in high dose rate brachytherapy. Med Phys $1: 224-232$

19. Hardcastle N, Cutajar DL, Metcalfe PE, et al. (2010) In vivo real-time rectal wall dosimetry for prostate radiotherapy. Phys Med Biol 13:38-59

20. Qi Z-Y, Deng X-W, Huang S-M, et al. (2007) Verification of the plan dosimetry for high dose rate brachytherapy using metal-oxidesemiconductor field effect transistor detectors. Med Phys 6: 2007-2013

21. Qi ZY, Deng XW, Huang SM, et al. (2009) In vivo verification of superficial dose for head and neck treatments using intensity-modulated techniques. Med Phys 1:59-70

22. Qi Z-Y, Deng X-W, Huang S-M, et al. (2011) Real-Time In Vivo Dosimetry With MOSFET Detectors in Serial Tomotherapy for Head and Neck Cancer Patients. Int J Radiat Oncol Biol Phys 5:1581-1588

23. Church CA, Kuhn FA, Mikhail J, Vaughan WC, and Weiss RL (2008) Patient and surgeon radiation exposure in balloon catheter sinus ostial dilation. Otolaryngol Head Neck Surg 2:187-191

24. Miller DL, Balter S, Cole PE, et al. (2003) Radiation doses in interventional radiology procedures: the RAD-IR study: part II: skin dose. J Vasc Interv Radiol 8:977-990

25. Stecker MS, Balter S, Towbin RB, et al. (2009) Guidelines for patient radiation dose management. J Vasc Interv Radiol 7:263-273

26. Vano E, Gonzalez L, Ten JI, Fernandez JM, Guibelalde E, and Macaya C (2001) Skin dose and dose-area product values for interventional cardiology procedures. Br J Radiol 877:48-55

27. Balter S (2006) Methods for measuring fluoroscopic skin dose. Pediatr Radiol 2:136-40 
28. Johnson PB, Borrego D, Balter S, Johnson K, Siragusa D, and Bolch WE (2011) Skin dose mapping for fluoroscopically guided interventions. Med Phys 10:5490-5499

29. Khodadadegan Y, Zhang M, Pavlicek W, et al. (2011) Automatic monitoring of localized skin dose with fluoroscopic and interventional procedures. J Digit Imaging 4:626-639

30. Casselden PA (1988) Ocular lens dose in cerebral vascular imaging. Br J Radiol 723:202-204

31. Mustafa AA and Janeczek J (1989) Organ doses from cardiac and carotid digital subtraction angiography. Br J Radiol 741:838-842

32. Berthelsen B and Cederblad A (1991) Radiation doses to patients and personnel involved in embolization of intracerebral arteriovenous malformations. Acta Radiol 6:492-497 


\section{List of figures:}
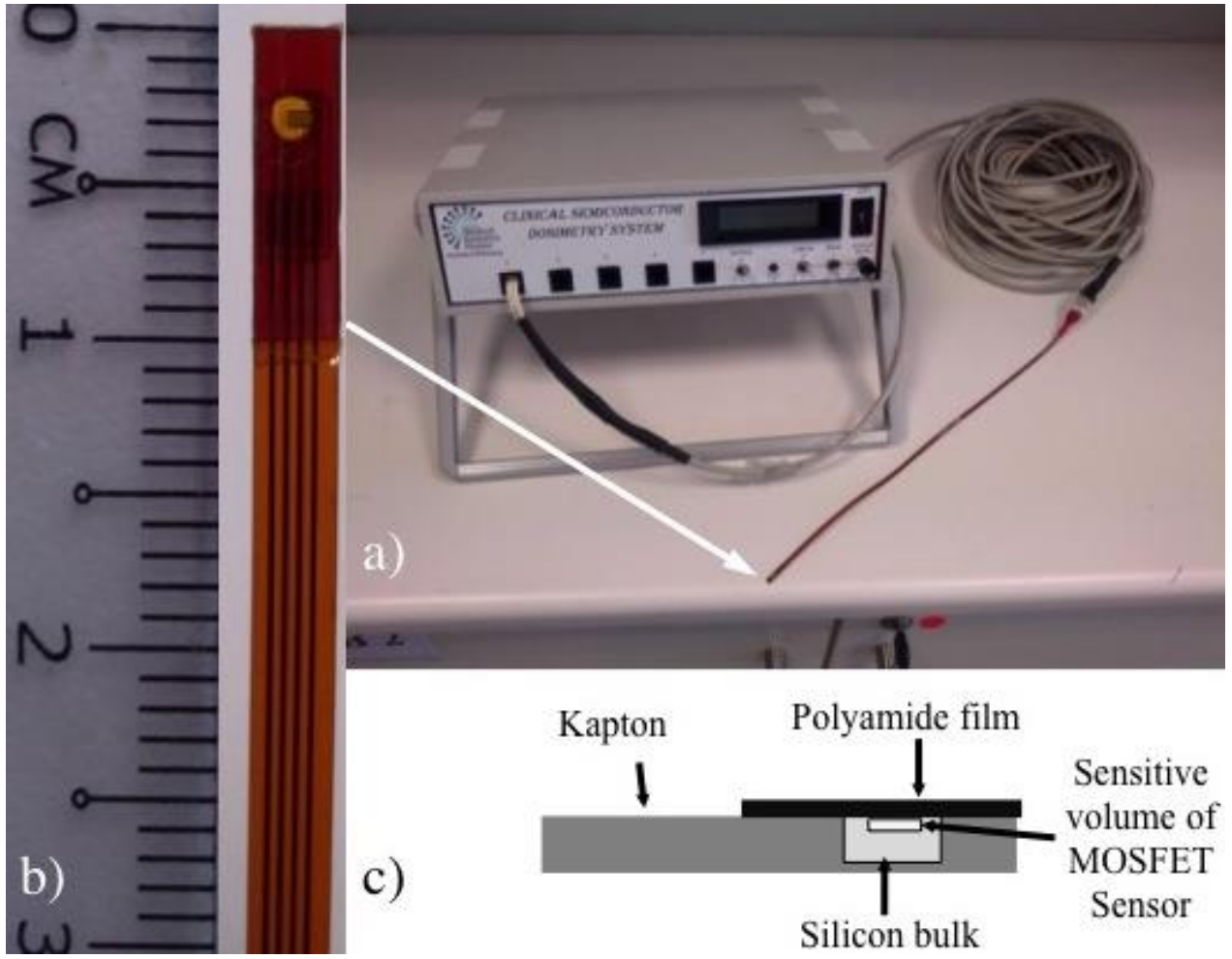

Figure 1 (a) MOSkin dosimetry system (b) MOSkin detector and (c) MOSkin detector components.

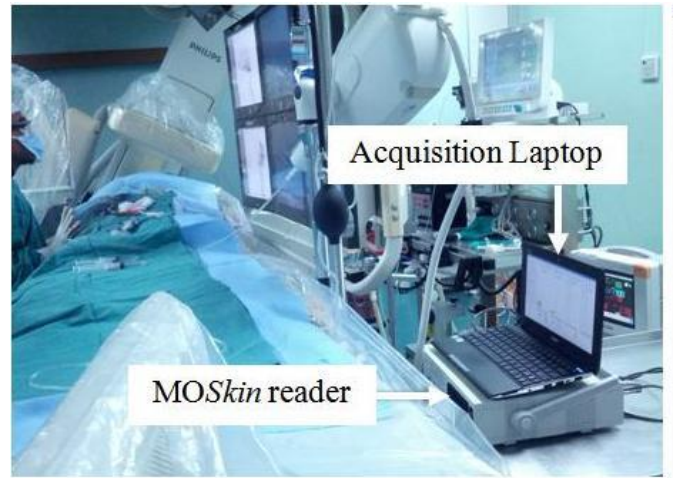

a)

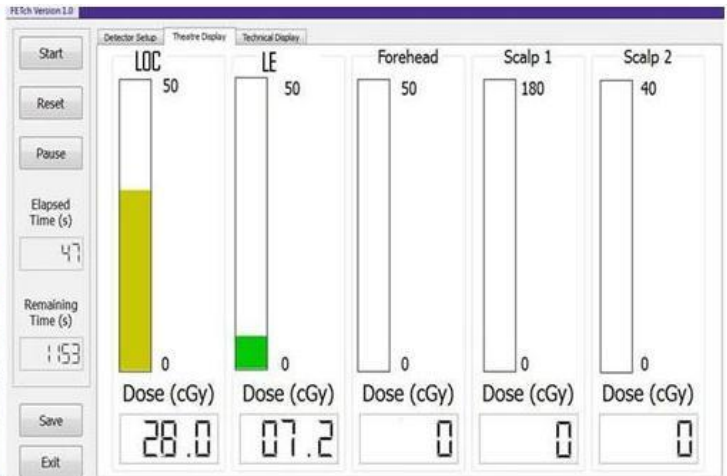

b) 
Figure 2 (a) MOSkin dosimetry system was placed at treatment room and accumulated dose values were displayed using the FETch software in front of the interventionalist and the radiographer during treatment procedures. (b) FETch display showing the accumulated dose values.

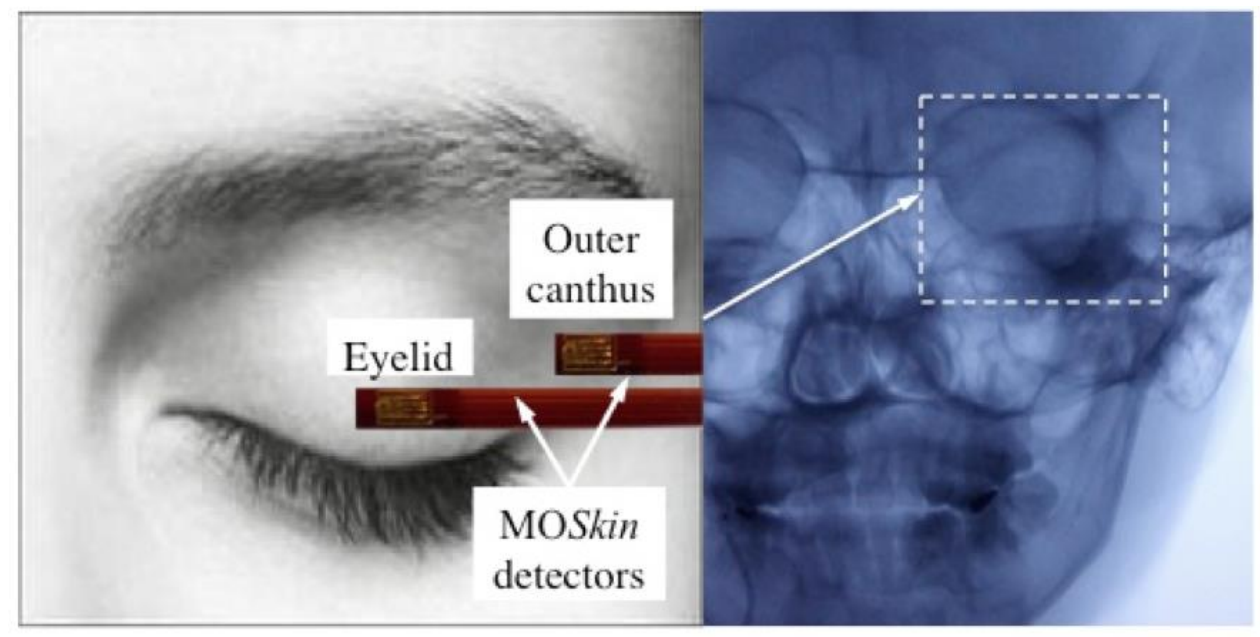

a)

b)

Figure 3 (a) The MOSkin detectors were positioned on the left eyelid and left outer canthus regions during interventional procedures. (b) This detector is almost invisible on the displayed image. 


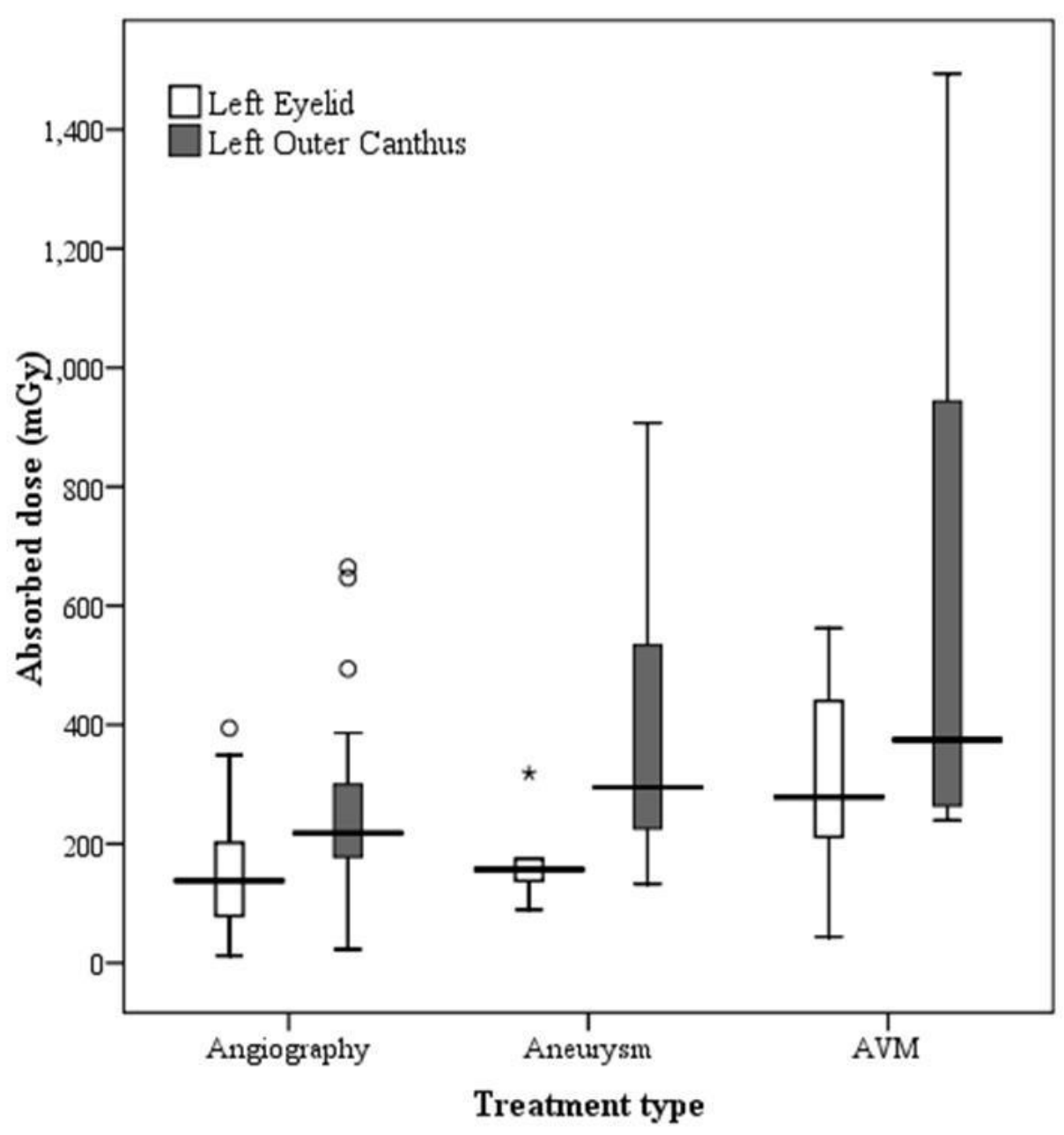

Figure 4 The boxplot shows the median and distribution of the dose delivered to the outer canthus and eyelid areas for each treatment procedure for the 35 participating patients, comprising 19 diagnostic angiographies, 8 treatments of cerebral aneurysms, and 8 embolizations of AVMs. 

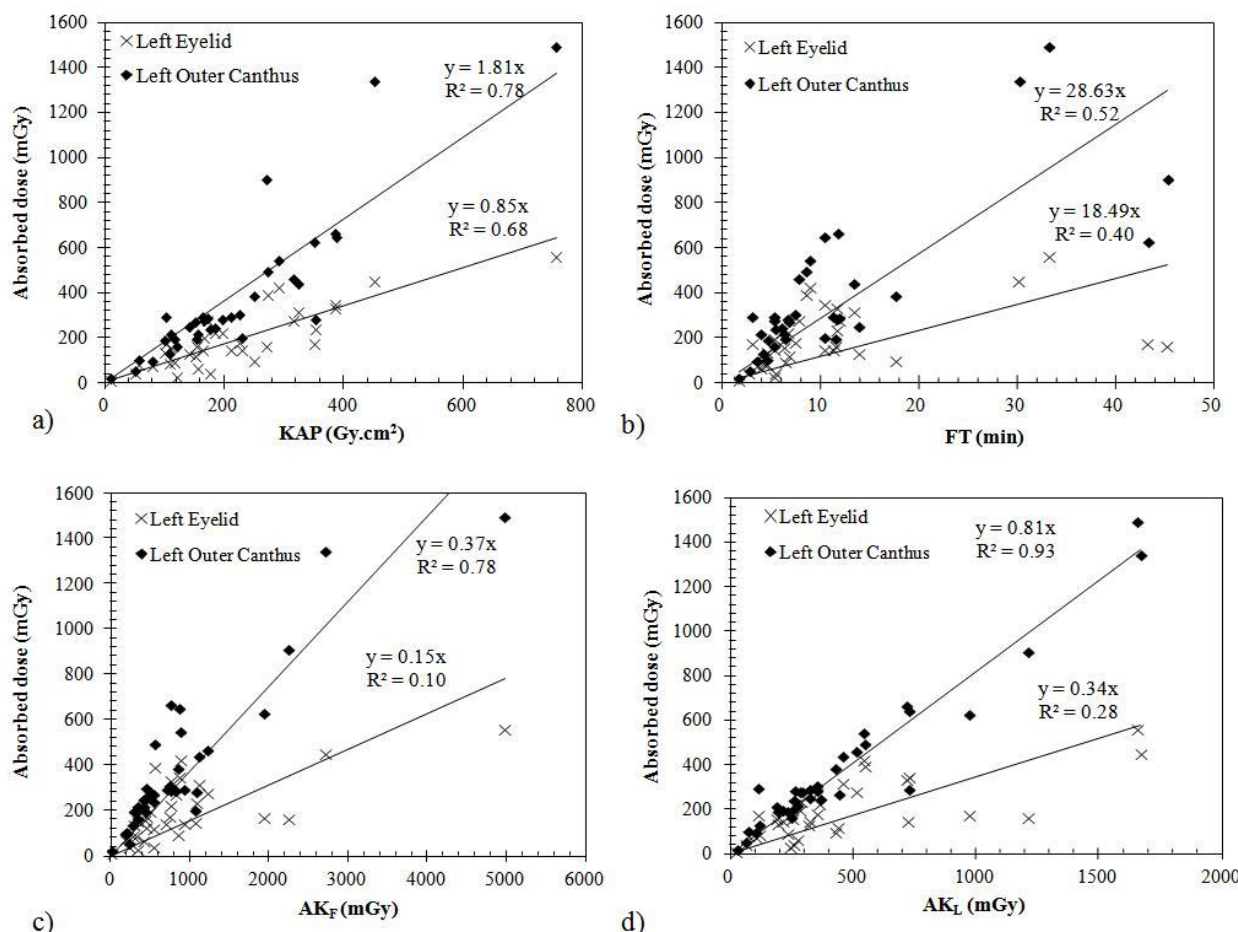

d)

Figure 5 Correlation between the measured dose to left outer canthus and left eyelid regions to (a) KAP, (b) FT, (c) $\mathrm{AK}_{\mathrm{L}}$ and (d) $\mathrm{AK}_{\mathrm{F}}$. 


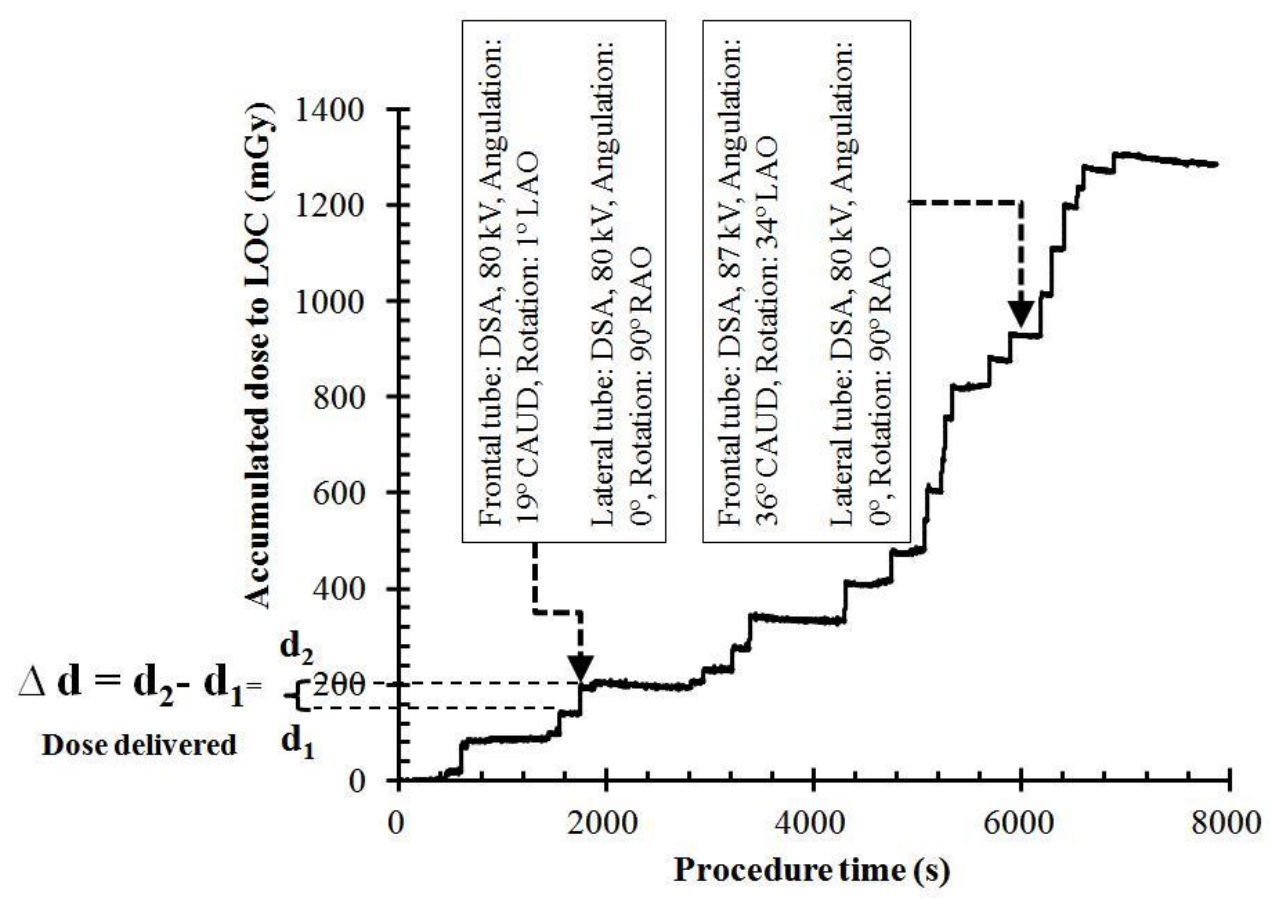

Figure 6 The accumulated dose trend line at LOC for an AVM procedure. From the realtime response pattern of the MOSkin detector, it is possible to investigate the dose delivered to the patients. The temporal dose pattern allows us to evaluate the contribution of each exposure to dose delivery to the patient's eye. Two particular exposures were labeled in this graph, $\mathrm{d} 1$ is dose before exposure and $\mathrm{d} 2$ is the dose after exposure. The increment dose $(\Delta \mathrm{d})$ indicates the absorbed 


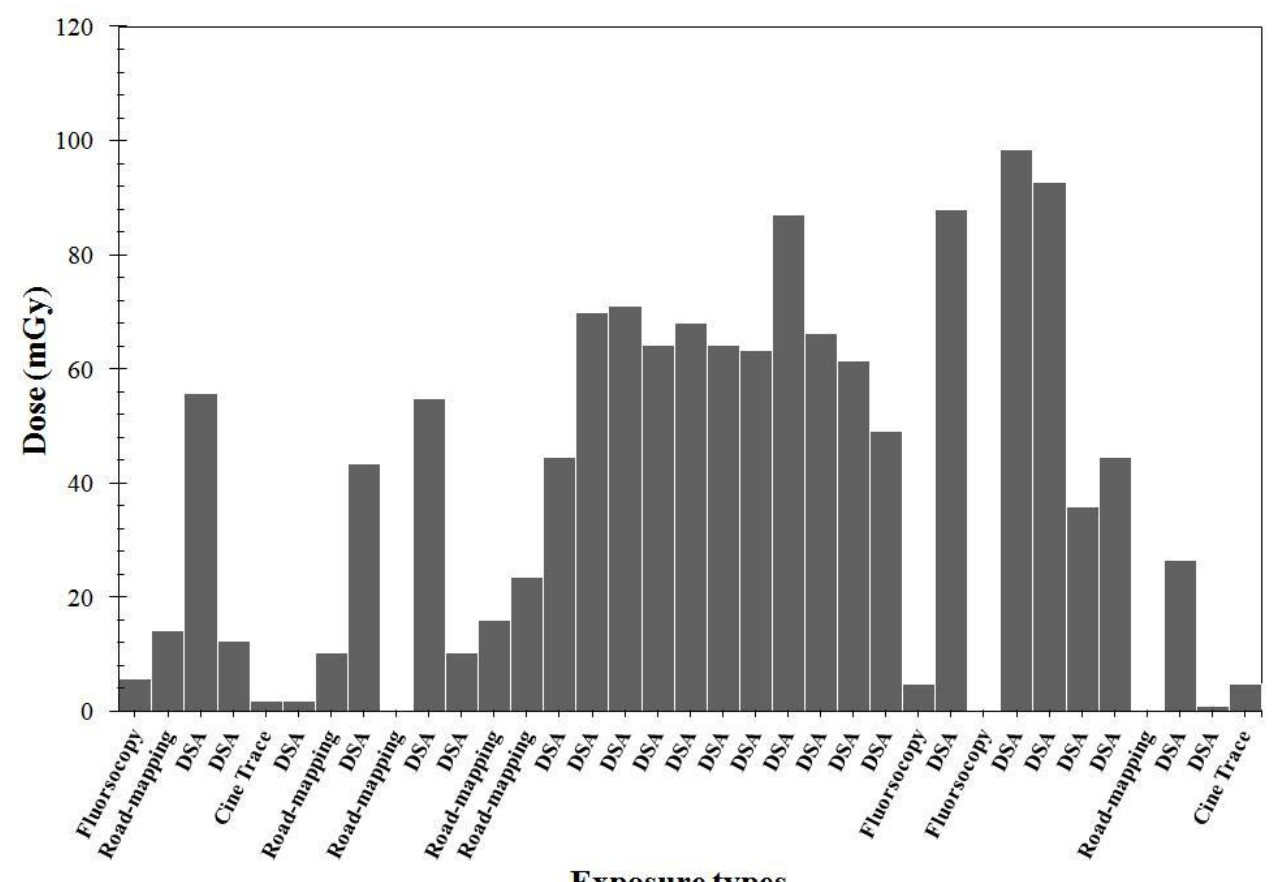

Exposure types

Figure 7 The dose delivered to the patient's LOC depicted as contribution of different types of exposure (e.g. fluoroscopy, road mapping, DSA and Cine Trace).

\section{List of Tables:}

Table 1 Exposure parameters and dose delivered to LE and LOC areas, averages, medians, and 95th percentiles. 


\begin{tabular}{|c|c|c|c|c|c|c|}
\hline & KAP $\left(\mathbf{G y} . \mathbf{c m}^{2}\right)$ & $\mathbf{A K}_{\mathrm{F}}(\mathbf{m G y})$ & $\mathbf{A K}_{\mathrm{L}}(\mathbf{m G y})$ & FT (min) & LE Dose (mGy) & LOC Dose (mGy) \\
\hline \multicolumn{7}{|c|}{ Angiography } \\
\hline Average & 178.8 & 512.1 & 302.3 & 7.2 & 155.0 & 267.8 \\
\hline Median & 154.9 & 430.9 & 264.0 & 6.5 & 137.9 & 218.2 \\
\hline $95 \%$ & 385.5 & 893.5 & 716.9 & 12.4 & 353.4 & 648.8 \\
\hline \multicolumn{7}{|c|}{ Aneurysm } \\
\hline Average & 211.7 & 1060.5 & 516.0 & 18.2 & 168.4 & 393.0 \\
\hline Median & 196.6 & 997.5 & 388.8 & 12.4 & 157.1 & 294.9 \\
\hline $95 \%$ & 342.1 & 2139.2 & 1125.6 & 44.6 & 268.8 & 809.4 \\
\hline \multicolumn{7}{|l|}{ AVM } \\
\hline Average & 314.8 & 1513.5 & 705.3 & 13.7 & 308.4 & 612.3 \\
\hline Median & 238.6 & 855.4 & 439.4 & 8.4 & 278.6 & 374.9 \\
\hline $95 \%$ & 649.8 & 4193.3 & 1664.2 & 32.2 & 524.7 & 1441.4 \\
\hline
\end{tabular}

KAP indicates kerma area-product; $\mathrm{AK}_{\mathrm{F}}$, air-kerma for frontal tube; $\mathrm{AK}_{\mathrm{L}}$, air-kerma for lateral tube; $\mathrm{FT}$, total fluoroscopic time; $\mathrm{LE}$, left eyelid; LOC, left outer canthus.

Table 2 Comparison of published data on eye doses for neuro-interventional radiology procedure.

\begin{tabular}{|c|c|c|c|c|c|c|c|c|}
\hline \multirow[t]{2}{*}{ Ref. \& Year } & \multirow[t]{2}{*}{ Interventional procedure } & \multirow{2}{*}{$\begin{array}{l}\text { Patient } \\
\text { number }\end{array}$} & \multirow{2}{*}{$\begin{array}{l}\text { Detector } \\
\text { type }\end{array}$} & \multirow{2}{*}{$\begin{array}{c}\text { Mean } \\
\text { KAP } \\
\left(\text { Gy.cm }{ }^{2}\right)\end{array}$} & \multirow{2}{*}{$\begin{array}{c}\text { Mean } \\
\text { Fluoroscopy } \\
\text { time (min) }\end{array}$} & \multirow[t]{2}{*}{ Detector position } & \multicolumn{2}{|c|}{ Eye lens dose (mGy) } \\
\hline & & & & & & & Maximum & Average \\
\hline [32] (1991) & Embolization & 5 & TLD $^{1}$ & $\cdot$ & 59.8 & Lateral margin & 139 & 90 \\
\hline \multirow[t]{4}{*}{ [13] (1998) } & Diagnostic & 15 & TLD & - & 0.4 & I-S margins ${ }^{2}$ & 2 & 1.1 \\
\hline & & & & & & Lateral margin & 150 & 99 \\
\hline & LDS $^{3}$ & 10 & TLD & $\cdot$ & 5.6 & I-S margins & 66 & 38 \\
\hline & & & & & & Lateral margin & 294 & 176 \\
\hline [15] (2000) & $\operatorname{DSP}^{4}$ & 10 & TLD & - & 3.9 & I-S margins & 68 & 38 \\
\hline [12] (2003) & Embolization & 30 & TLD & 106.0 & 14.0 & - & 500 & 60 \\
\hline [17] (2008) & $\begin{array}{c}\text { Therapeutic interventional } \\
\text { radiology }\end{array}$ & 28 & $\mathrm{PLD}^{5}$ & - & 55.6 & Lateral margin & 2079 & 380 \\
\hline \multirow[t]{3}{*}{ [16] (2010) } & Diagnostic & 19 & TLD & 54.7 & 6.9 & Left Eyelid & - & 7.8 \\
\hline & Coiling & 27 & TLD & 121.0 & 32.0 & Left Eyelid & 515 & 51 \\
\hline & Embolization & 25 & TLD & 189.0 & 39.8 & Left Eyelid & 289 & 71 \\
\hline \multirow[t]{4}{*}{ This study } & Diagnostic & 19 & MOSkin & 178.8 & 7.2 & Left Eyelid & 394 & 155 \\
\hline & & & & & & Lateral margin $\left(\operatorname{LOC}^{6}\right)$ & 665 & 268 \\
\hline & Embolization & 16 & MOSkin & 314.7 & 15.9 & Left Eyelid & 563 & 238 \\
\hline & & & & & & Lateral margin (LOC) & 1492 & 502 \\
\hline $\begin{array}{l}\text { 'Thermolumi } \\
{ }^{2} \text { Inferior and }\end{array}$ & $\begin{array}{l}\text { it detector } \\
\text { or margins }\end{array}$ & $\begin{array}{l}{ }^{4} \text { Balloon } \mathrm{C} \\
{ }^{3} \text { Photolum }\end{array}$ & $\begin{array}{l}\text { stoplasty } \\
\text { cee glass do }\end{array}$ & & & & & \\
\hline${ }^{3}$ Lachrymal d & e system & ${ }^{6}$ Left Oute & & & & & & \\
\hline
\end{tabular}

